\title{
Detailed Study of Radon Spatial Anomaly in Tlamacas Mountain Area, Volcano Popocatepetl, Mexico
}

\author{
Anatolyi Kotsarenko1 ${ }^{*}$, Vsevolod Yutsis ${ }^{2}$, Vladimir Grimalsky ${ }^{3}$, Svetlana Koshevaya ${ }^{3}$ \\ ${ }^{1}$ Facultad de Ingeniería, Universidad Autónoma del Carmen, Cd. del Carmen, México \\ ${ }^{2}$ División de Geociencias Aplicadas, Instituto Potosino de Investigación Científica y Tecnológica, San Luis Potosí, \\ Mexico \\ ${ }^{3}$ Centro de Investigación en Ingeniería y Ciencias Aplicadas, Universidad Autónoma del Estado de Morelos, \\ Cuernavaca, México \\ Email: *kotsarenko@gmail.com, vsevolod.yutsis@ipicyt.edu.mx,v_grim@hotmail.com, svetlana@uaem.mx
}

Received 13 February 2016; accepted 14 March 2016; published 17 March 2016

Copyright (C) 2016 by authors and Scientific Research Publishing Inc.

This work is licensed under the Creative Commons Attribution International License (CC BY).

http://creativecommons.org/licenses/by/4.0/

CC) (i) Open Access

\section{Abstract}

Results of a soil radon survey accomplished by 2 different methods during 2 different periods in the area of Tlamacas Mountain are presented. The first study, carried out from 15-APR-2010 to 09-MAY-2010 in 30 measurement sites by means of CR39 solid state nuclear detectors, shows 2 active zones with intensive radon emanation with a characteristic dimension of about 300 meters located in the northwestern and western parts of the Mountain. The second survey, made on 05-JUL-2011 in 23 measurement sites with 10 min sampling by a SARAD RTM 1688 Radon/Thoron monitor, in contrast, revealed a sizeable area depleted in radon and 3 active areas of increased radon release in the lateral Mountain sides. These observed phenomena strengthen our assumption about the presence of an active geological structure in Tlamacas Mountain connected with a geodynamical processes in volcano Popocatepetl.

\section{Keywords}

Radon, Tlamacas, Mexico, Anomaly, Popocatepetl, Monitoring

\section{Introduction}

Our earlier studies in the volcano Popocatepetl area (Figure 1, Lat. $19.07^{\circ} \mathrm{N}$, Long. $98.63^{\circ} \mathrm{W}$, elevation $5465 \mathrm{~m}$ )

${ }^{*}$ Corresponding author.

How to cite this paper: Kotsarenko, A., Yutsis, V., Grimalsky, V. and Koshevaya, S. (2016) Detailed Study of Radon Spatial Anomaly in Tlamacas Mountain Area, Volcano Popocatepetl, Mexico. Open Journal of Geology, 6, 158-164. 


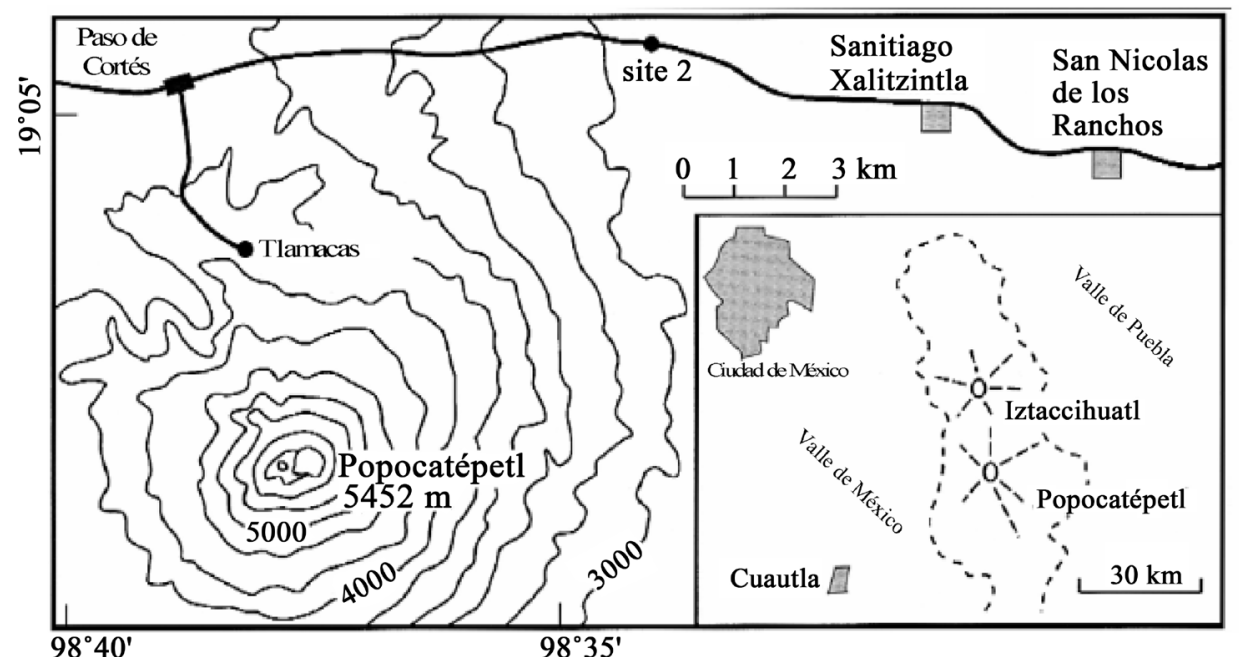

Figure 1. Volcano Popocatepetl, topographic map [2].

have shown the variety of anomalies in Radon behavior associated with volcanic activity [1]. Monitoring of soil radon release in 3 different volcanic sites has shown several cases of decreasing radon concentration during times of approaching moderate volcanic eruptions. A soil radon survey and gamma ray spectrometry revealed intensive radon and gamma ray emanation located in the area of Tlamacas Mountain; the radon concentrations in the Tlamacas area were 10 - 20 times greater than the background volcano values. A new conception of the coupling between the lithosphere and the atmosphere was also presented: intensive radon release modifies the electric circuit between the ground and thunderclouds, provoking micro-discharges in the air and attracting lightnings.

In order to interpret results on the correlation between radon behavior at Tlamacas station with moderate eruptions of volcano Popocatepetl, more studies in the Tlamacas area were desirable. Additionally, different questions in relation to the radon anomaly in Tlamacas Mountain (Figure 2), [1] have arisen. How homogeneous is the area of radon emanation in the Tlamacas area? Is the radon distribution the same at different times? The present article is devoted to a detailed study of the Radon release in the area of Tlamacas; the results were obtained at different times by two different radon survey methods. Similar radon surveys in volcano-tectonic geological structures have been carried out in different active volcanoes all over the world [2]-[6]. The current study aids in understanding the connection of Tlamacas Mountain with the volcano Popocatepetl, which is of great importance for forecasting its eruptive activity.

\section{Radon Survey in the Tlamacas Area}

\subsection{Equipment and Method}

CR39 solid state nuclear track detectors (SSNTD) were used to determine the detailed distribution of the soil radon concentration in the Tlamacas Mountain in our first survey. Plastic glasses with suspended CR39 detectors inside were buried in $40 \mathrm{~cm}$-deep holes in the 30 measurement sites during 15-17-APR-2010 and recovered 09-MAY-2010. The total deployment time of the detectors varied between 22 days 4 hours and 24 days 6 hours.

CR39 was developed by Cartwright [7]. It is a plastic polymer (POLYALLY-DIGLYCOL-CARBONATED or PADC) that belongs to the class of polyesters. This material has the characteristic of being susceptible to alpha particles resulting from radioactive decay of radon. The impacts of the particles with CR39 create damage on the surface of the detectors; the damage concentration is related to the radon concentration. Damage tracks can be highlighted through a chemical attack carried out using $\mathrm{KOH} 6.2 \mathrm{M}$, placed in an oven at a constant temperature of $60^{\circ} \mathrm{C}$ for 18 hours. During this chemical attack, the detectors are thinned, and the tracks of the damages are enlarged. After this process the tracks can be observed using an optical microscope.

The measurement of track density consists in hand-counting using pictures obtained through a digital camera installed on the microscope. The investigation area covers a surface of $3 \mathrm{~mm}^{2}$ for each detector and counting allows us to obtain the number of tracks per square centimeter $\left(\mathrm{tr} . / \mathrm{cm}^{2}\right)$. In this work we considered only circular 


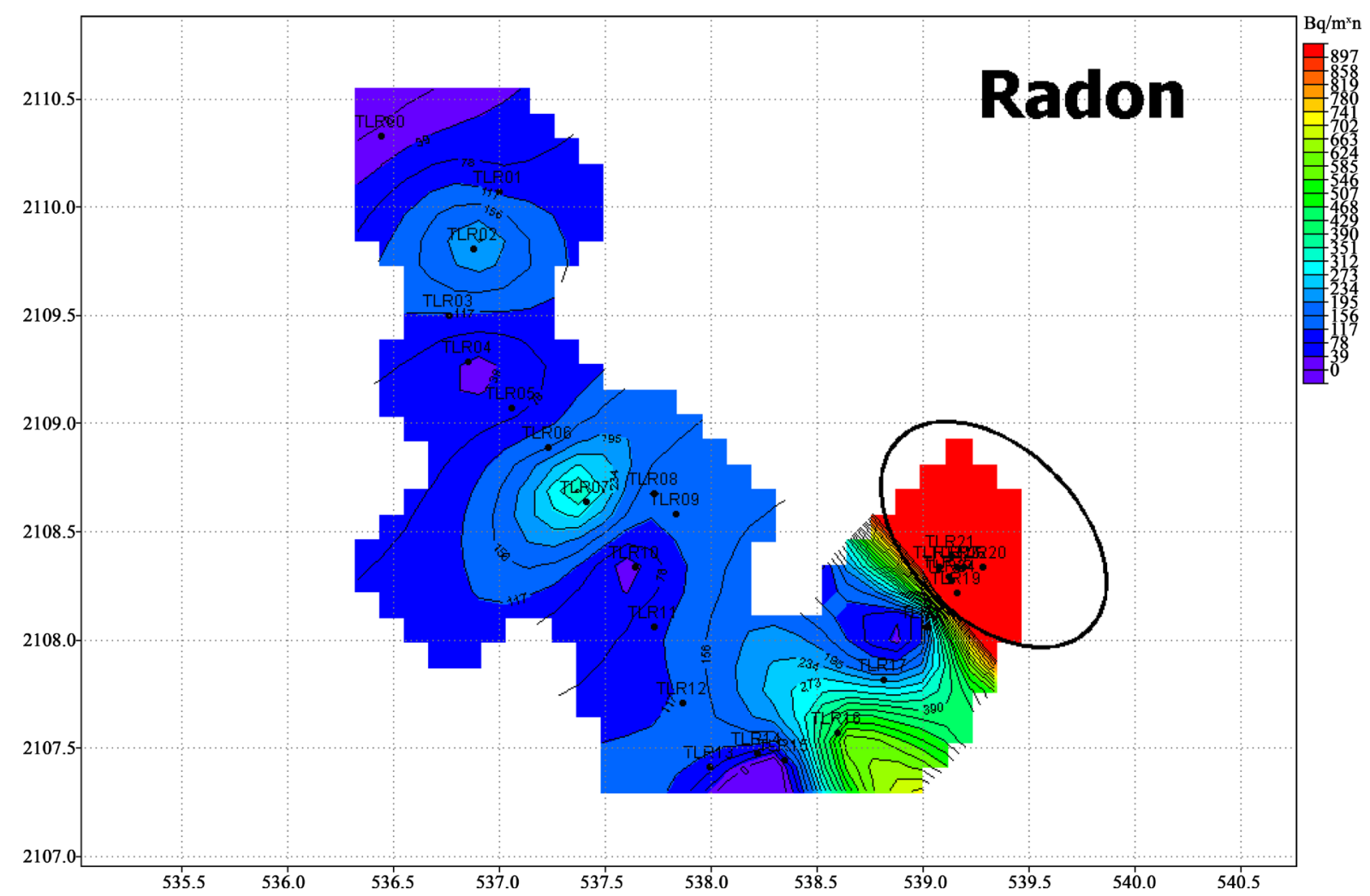

Figure 2. Radon concentration in the area of Tlamacas mountain (area marked by ellipse) and between Tlamacas and paso de cortes (top part of the map), 05-DEC-2009.

tracks with a white spot inside, which represent alpha particles that hit the surface of the CR39 detectors perpendicularly, in order to avoid manufacturing defects.

Absolute values in $\mathrm{Bq} / \mathrm{m}^{3}$ are not possible, because we did not use the holders, which prevent radon's daughter nuclides (e.g. ${ }^{218} \mathrm{Po}$ ) from damaging the CR39 sensors. Instead we obtained relative values in $\mathrm{tr} . / \mathrm{cm}^{2}$, comparable with others collected in the same conditions and in the same area.

The SARAD RTM 1688 Radon/Thoron monitor was used for our second survey, which was carried out on 05-JUL-2011. Measurement of radon concentration by this instrument is based on the alpha spectrometry method: the concentration of radon is proportional to the number of alpha particles emitted during ${ }^{222} \mathrm{Rn}$ decay in the ionization chamber. The concentration of radon released was measured with 10 min sampling time in 23 sites on Tlamacas Mountain.

Additionally, portable solid state detectors SARAD Scout were used in our preceding study for obtaining radon map between Paso de Cortes and Tlamacas and in the Tlamacas Mountain (Figure 1). Details and limitation of this study can be found in [1].

\subsection{Results and Discussion}

Our results (Table 1 and Table 2) are presented in the Figure 3. First, one can see that the spatial distribution of radon release on Tlamacas Mountain is not homogeneous, it has fine structures. Our first measurements with the CR39 detectors reveal 2 active spots of intensive radon emanation with a diameter of about $300 \mathrm{~m}$ : one on the northwestern side of the mountain and another on the western side. Our second measurements with the SARAD RTM 1688 monitor show a completely different radon distribution: radon release is observed in three different mountain sides meanwhile the topside is depleted in radon.

What can explain such a considerable difference between 2 periods of measurements? Radon emanation depends on a variety of factors, such as deposits of radioactive elements, soil porosity and penetrability, meteorological conditions (almost importantly atmospheric pressure and humidity), the presence of active tectonic structures, and increased fracturing. Naturally, the atmosphere pressure was equal for all measurement sites in so 
Table 1. Concentration of radon obtained with CR39 during April-May 2010.

\begin{tabular}{|c|c|c|c|}
\hline Lat ${ }^{\circ} \mathrm{N}$ & Long ${ }^{\circ} \mathrm{W}$ & Time (days) & Tr. $/ \mathrm{cm}^{2}$ \\
\hline 19.061 & 98.633 & 24.247 & 1832 \\
\hline 19.062 & 98.632 & 24.235 & 480 \\
\hline 19.063 & 98.631 & 24.222 & 420 \\
\hline 19.064 & 98.630 & 24.211 & 2042 \\
\hline 19.065 & 98.630 & 24.199 & 1141 \\
\hline 19.066 & 98.628 & 24.186 & 1502 \\
\hline 19.067 & 98.628 & 24.170 & 420 \\
\hline 19.068 & 98.627 & 24.151 & 1712 \\
\hline 19.068 & 98.627 & 24.142 & 3273 \\
\hline 19.067 & 98.629 & 24.133 & 240 \\
\hline 19.067 & 98.628 & 24.128 & 6637 \\
\hline 19.067 & 98.625 & 24.153 & 571 \\
\hline 19.067 & 98.623 & 24.139 & 511 \\
\hline 19.068 & 98.621 & 24.128 & 691 \\
\hline 19.066 & 98.621 & 24.118 & 1141 \\
\hline 19.066 & 98.623 & 24.118 & 1021 \\
\hline 19.064 & 98.626 & 24.104 & 180 \\
\hline 19.064 & 98.627 & 24.104 & 210 \\
\hline 19.066 & 98.629 & 23.281 & 60 \\
\hline 19.066 & 98.630 & 23.260 & 571 \\
\hline 19.067 & 98.630 & 23.247 & 150 \\
\hline 19.068 & 98.630 & 23.240 & 270 \\
\hline 19.069 & 98.629 & 23.229 & 961 \\
\hline 19.069 & 98.628 & 23.219 & 661 \\
\hline 19.069 & 98.627 & 22.344 & 601 \\
\hline 19.068 & 98.625 & 22.337 & 811 \\
\hline 19.067 & 98.626 & 22.330 & 1351 \\
\hline 19.067 & 98.628 & 22.215 & 1832 \\
\hline 19.067 & 98.628 & 22.198 & 751 \\
\hline 19.066 & 98.628 & 22.179 & 3724 \\
\hline
\end{tabular}

localized an area. A previous study [1] has also excluded the presence of superficial radioactive deposits. However, we cannot rule out the influence of environmental factors together with weather conditions. Our first measurements were realized during a long period of fair weather, whereas the second survey was performed during the rainy season. Tlamacas Mountain is inhomogeneously covered by pine trees, and atmospheric precipitation in covered places could make an impact upon soil humidity and even its penetrability. This factor could essentially reduce radon release. In addition, the different methodologies of the measurements require care in interpretation. Results obtained with the CR39 detectors display the integrated radon contribution during over 3 weeks of measurements whereas the RTM 1688 monitor estimates the current level of radon emanation. Strictly, the reliability factor is higher for CR39 results comparing to the RTM 1688 data.

The above mentioned impact may give up to $30 \%$ of deviation in obtained results, but the difference between the two maps is still larger. Instead, the governing factor which may explain the observed phenomenon can be the geological origin of the Tlamacas Mountain. Preliminary, we infer that Tlamacas Mountain resulted from volcanic activity and it likely functions as a parasite crater of volcano Popocatepetl at some time. Hence it may remain an active geological structure, as also confirmed by different phenomena discussed in [1]. In this inter- 
Table 2. Concentration of radon obtained with CR39 during April-May 2010.

\begin{tabular}{cccc}
\hline Lat ${ }^{\circ} \mathrm{N}$ & Long ${ }^{\circ} \mathrm{W}$ & $\mathrm{Rn}, \mathrm{Bq} / \mathrm{m}^{3}$ & $\mathrm{Rn}$ err, \% \\
\hline 19.0671 & 98.6281 & $\mathbf{8 0 0}$ & 29 \\
19.0670 & 98.6292 & $\mathbf{6 5 0 0}$ & 11 \\
19.0674 & 98.6288 & $\mathbf{2 3 0 6}$ & 19 \\
19.0674 & 98.6285 & $\mathbf{1 0 6 8}$ & 30 \\
19.0674 & 98.6281 & $\mathbf{1 3 2 9}$ & 23 \\
19.0674 & 98.6278 & $\mathbf{1 0 2 6}$ & 29 \\
19.0673 & 98.6274 & $\mathbf{3 0 0 7}$ & 15 \\
19.0671 & 98.6290 & $\mathbf{8 3 9}$ & 29 \\
19.0672 & 98.6284 & $\mathbf{1 1 0 8}$ & 30 \\
19.0670 & 98.6283 & $\mathbf{3 5 5}$ & 53 \\
19.0666 & 98.6283 & $\mathbf{2 4 0}$ & 62 \\
19.0666 & 98.6286 & $\mathbf{6 2 9}$ & 33 \\
19.0662 & 98.6288 & $\mathbf{5 3 0}$ & 38 \\
19.0661 & 98.6292 & $\mathbf{3 8 1}$ & 53 \\
19.0664 & 98.6292 & $\mathbf{5 7 5}$ & 38 \\
19.0669 & 98.6292 & $\mathbf{6 0 2}$ & 35 \\
19.0669 & 98.6296 & $\mathbf{5 3 1}$ & 40 \\
19.0665 & 98.6297 & $\mathbf{2 2 5}$ & 68 \\
19.0660 & 98.6297 & $\mathbf{1 4 0}$ & 71 \\
19.0655 & 98.6294 & $\mathbf{4 9 0}$ & 38 \\
19.0656 & 98.6291 & $\mathbf{1 9 2 9}$ & 20 \\
19.0658 & 98.6284 & $\mathbf{1 6 7 5}$ & 55 \\
19.0669 & 98.6274 & $\mathbf{4 0 7}$ & \\
\hline
\end{tabular}

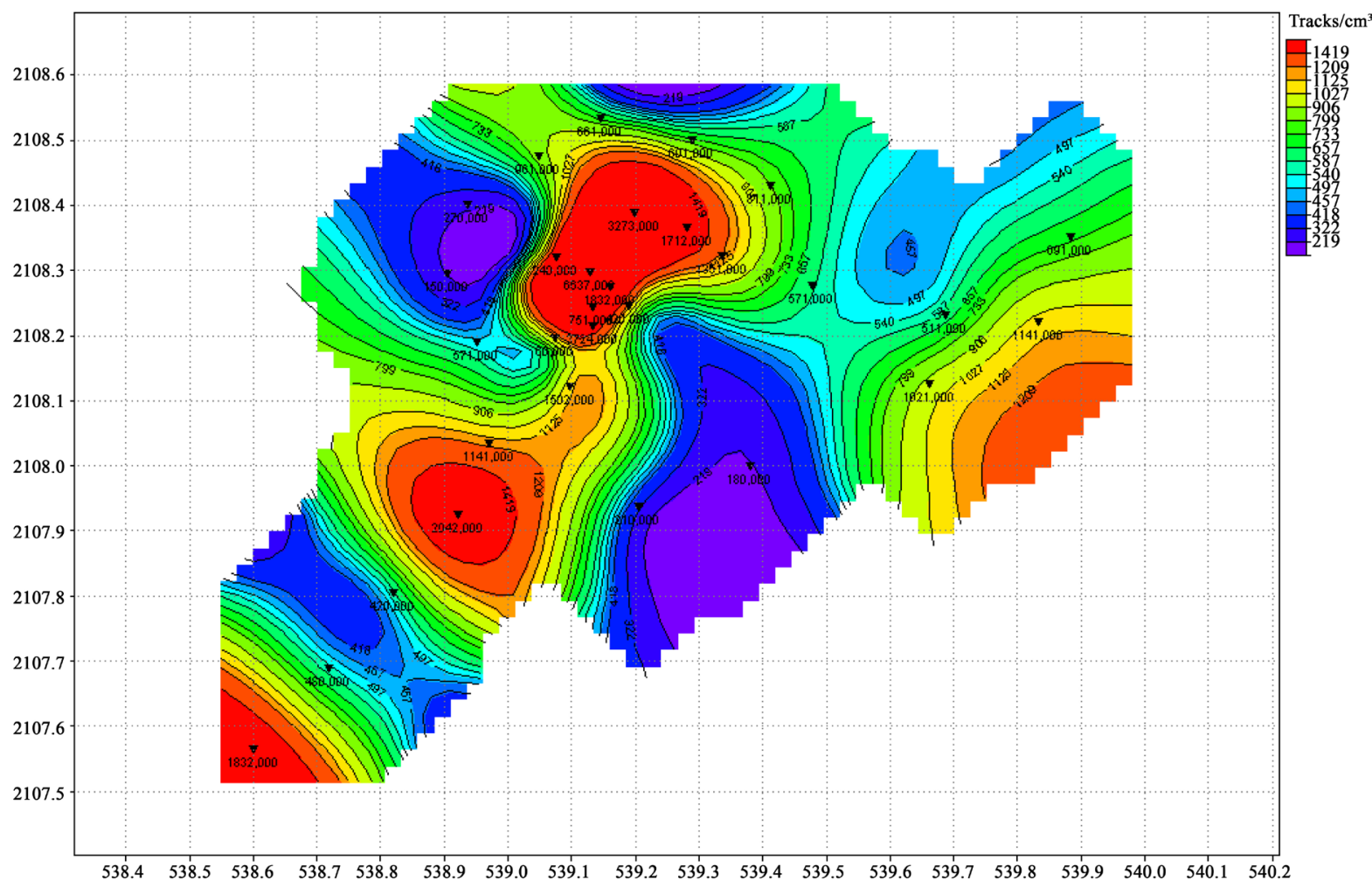

(a) 


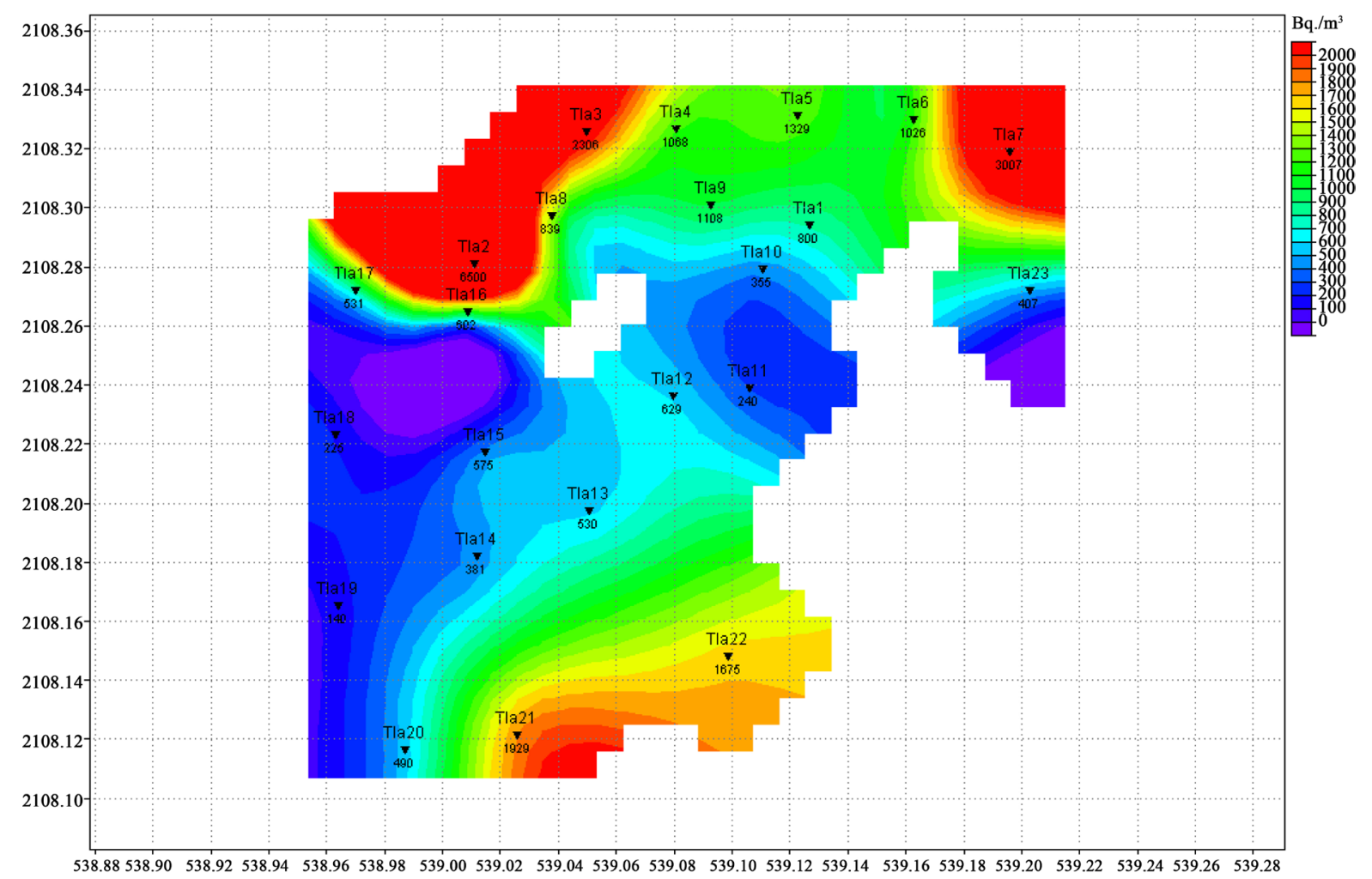

(b)

Figure 3. Detailed distribution of Radon concentration in Tlamacas Mountain: (a) map obtained with CR39, 15-17-APR9-MAY 2010; (b) map obtained with SARAD RTM 1688, 05-JUL-2011. The top of Tlamacas Mountainis approximately in the center of each picture.

pretation, the difference between local radon behavior may be explained by a continued geodynamical processes in the Mountain depths.

\section{Conclusions}

The presented results of two soil radon surveys realized at a different time have confirmed our earlier suppositions. Being an active geological structure, Tlamacas Mountain emanates radon in a spatially heterogeneous manner that is non-stationary in time.

It is highly desirable to supplement our current studies by methods of geophysical prospecting and structural geology which may help us to make a scientific leap in understanding the nature of the Mountain and explain better a series of geophysical phenomena observed in its area.

The observed phenomena have substantial significance for our monitoring of geophysical parameters in the Tlamacas Mountain area for the purpose of forecasting eruptive activity of the volcano Popocatepetl.

\section{Acknowledgements}

This work was partially funded under Mexican UNAM DGAPA PAPIIT projects IN120808 and IN109411. Authors thank G. Espinoza, M. Fazio, P. Perego, F. Foglia, G. Norini and G. Groppelli for their help with measuring and processing of CR39 detectors. We are also thankful to J. Berger, X. Carriere, R. Hernández Cardenas and L.J. Cortes Leyva for their participation in measurements with SARAD RTM 1688.

\section{References}

[1] Kotsarenko, A., Grimalsky, V., Yutsis, V., Pérez, L.I.M., Bravo Osuna, A.G., Koshevaya, S., Perez Enriquez, R., Urquiza Beltran, G., Villegas Ceron, R.A., Lopez Cruz Abeyro, J.A. and Valdes Gonzales, C. (2012) Experimental Studies of Anomalous Radon Activity in the Tlamacas Mountain, Popocatepetl Volcano Area, Mexico: New Tools to 
Study Lithosphere-Atmosphere Coupling for Forecasting Volcanic and Seismic Events. Annals of Geophysics, SI: Earthquake Precursors, 55, 109-118.

[2] Goff, F., Janik, C.J., Delgado, H., Werner, C., Counce, D., Stimac, J.A., Siebe, C., Love, S.P., Williams, S.N., Fischer, T. and Johnson, L. (1998) Geochemical Surveillance of Magmatic Volatiles at Popocatepetl Volcano, Mexico. Gelogical Society of America Bulletin, 110, 695-710. http://dx.doi.org/10.1130/0016-7606(1998)110<0695:GSOMVA>2.3.CO;2

[3] Martín, M.C., Ahijado, A., De la Nuez, J., Quesada, M.L., Steinitz, G., Vulkan, U. and Eff-Darwich, A. (2003) Radon Survey at La Palma Island (Canary Islands): First Results. Vulcânica, I, 113-116.

[4] Burton, M., Neri, M. and Condarelli, D. (2004) High Spatial Resolution Radon Measurements Reveal Hidden Active Faults on Mt. Etna. Geophysical Research Letters, 31, L07618. http://dx.doi.org/10.1029/2003GL019181

[5] Hernandez, P., Perez, N., Salazar, J., Reimer, M., Notsu, K. and Wakita, H. (2004) Radon and Helium in Soil Gases at Canadas Caldera, Tenerife, Canary Islands, Spain. Journal of Volcanology and Geothermal Research, 131, 59-76. http://dx.doi.org/10.1016/S0377-0273(03)00316-0

[6] Pulinets, S.A. and Boyarchuk, K.A. (2004) Ionospheric Precursors of Earthquakes. Springer, Berlin, Heidelberg, New York.

[7] Cartwright, B.G., Shirk, E.K. and Price, P.B. (1978) A Nuclear-Track-Recording Polymer of Uniquesensitivity and Resolution. Nuclear Instruments and Methods, 153, 457-460. http://dx.doi.org/10.1016/0029-554X(78)90989-8 